\title{
The Nobel Memorial Prize for Clive W. J. Granger
}

\author{
David F. Hendry* \\ Economics Department, Oxford University \\ February 1, 2004
}

\section{Introduction}

Clive Granger developed the econometric foundations for analyzing and modeling non-stationary macroeconomic time series, forging an approach that has become the dominant paradigm in empirical macroeconomic research. From a critique of potential 'nonsense regressions' in applied econometric models of non-stationary data, Granger's concept of cointegration facilitates the merging in a unified framework of economic theory about equilibrium relationships with dynamic econometric models of short-run behaviour. This provided a remarkable leap forward in the empirical analysis of macroeconomic relationships, and in testing macroeconomic theories, extending to non-stationary macroeconomic time series the formulation by Nobel Laureate Trygve Haavelmo of an economy as a system of simultaneous stochastic relationships. This research has spawned an industry, veritably 'opening a door' to powerful ideas and procedures that many have followed, and helped extend, ever since: there are in excess of 2800 citations to his joint paper on cointegration with Robert Engle, who shared the 2003 Prize. Major policy institutions around the world now use empirical econometric models in which cointegrated relations determine the long-run outcomes. In recognition of his achievements, Clive Granger was awarded The Sveriges Riksbank Prize in Economic Science in Memory of Alfred Nobel in October 2003.

The first really influential research of Clive Granger was his formalization of causality (via predictability), which made that concept operational, and thus testable. Most economic relations are inexact, so stochastic formulations are inevitable, leading to his idea of evaluating causality in terms of changes to the joint distributions of the observables. Granger (1969) is one of the most influential papers in econometrics, and has been cited on more than 1200 occasions. A vast literature has also followed this path-breaking work. 'Granger-causality' provided macroeconomics with empirical tests of economic theories that implied time-related causal relationships between economic variables, a possibility that has been implemented many times over during the last 30 years.

At about the same time, Granger helped advance the theory of economic forecasting in a series of major publications. In particular, John Bates and Granger (1969) proposed a simple but powerful idea, namely that pooled forecasts might dominate the best of a set of separate forecasts. Finally, Granger has made important contributions to financial econometrics, one of the most rapidly growing fields in economics. His related work on long memory, non-linearity, commodities, aggregation and stock market behaviour, much of which is still continuing, has shaped the research agenda of many fi-

\footnotetext{
*Financial support from the UK Economic and Social Research Council under a Professorial Research Fellowship is gratefully acknowledged. I am indebted to Timo Teräsvirta for his invaluable inputs to the paper, and to Gunnar Bårdsen, Jesus Gonzalo, and Neil Shephard for helpful comments on an earlier draft.
} 
nancial econometricians, and given rise to a large number of applications. A list of his publications (as of its appearance) is provided in Phillips (1997), and a complete set is available on his web site (http://econ.ucsd.edu/ ${ }^{\sim}$ cgranger/). Ghysels, Swanson and Watson (2001) contains reprints of many of his published papers.

This article discusses, albeit briefly, Granger's most important contributions to economics, focusing on cointegration. The story of the discovery of cointegration, like many scientific discoveries, is one involving false avenues, half understood solutions, partial insights, and persistent anomalies, all finally resolved by the major breakthrough. It began in the last part of the nineteenth century, with an effort to understand why 'peculiar' correlations (such as a positive association between births and the number of storks in Stockholm) turned up surprisingly often, and led to several steps forward, addressed in section 2. Then the story progresses to the role of equilibrium in non-stationary time series (i.e., ones where some aspects of the distribution changes over time), considered in section 3. The saga concluded with a general formulation for a widely occurring phenomenon in economics, described in section 4 . The remainder of the article then briefly considers Granger's work on causality in section 5; long memory in section 6; non-linear modelling in section 7; and economic forecasting in section 8. Section 9 concludes.

\section{Nonsense regressions}

The first statistician to formally analyze, and name, nonsense regressions was Udny Yule (1926). He established the mis-behaviour of the conventional correlation coefficient when the two variables under study were integrated, either once (now denoted I(1)), or twice (I(2)). Consider a homoscedastic, random variable $\epsilon_{t}$ independently drawn from a normal distribution with mean zero and variance $\sigma^{2}$, then $y_{t}$ and $s_{t}$ are respectively $\mathrm{I}(1)$ and $\mathrm{I}(2)$ if:

$$
y_{t}=\sum_{i=0}^{t} \epsilon_{i} \text { and } s_{t}=\sum_{j=0}^{t} y_{j} .
$$

Notice that $\Delta y_{t}=y_{t}-y_{t-1}=\epsilon_{t}$ and $\Delta s_{t}=y_{t}$ so $\Delta^{2} s_{t}=\epsilon_{t}$, and hence differencing once or twice respectively reduces these two constructed series to a non-integrated form (naturally denoted I(0)). Yule showed that the null of no relation would be rejected most of the time in the setting of integrated variables, even though the series were independently generated (reprinted in my book with Mary Morgan, Hendry and Morgan, 1995). However, worries about analyzing 'trending' variables were not new: for example, Yule (1897) had previously discussed spurious correlation where two variables were apparently related, but only because each was related to a third. This research was the source of Maynard Keynes (1940) famous quote in reviewing Jan Tinbergen (1940) about the 'mine [Mr Yule] sprang under the contraptions of optimistic statisticians'. Unfortunately, modern parlance has blurred this distinction, and both are now referred to generically as 'spurious' relations. Shortly after Yule's first work, in his investigation of the correlation between marriage rates and 'trade', R.H. Hooker (1901) successfully discriminated aspects of their relationship due to trend effects and those due to 'oscillations', as well as considering the impact of regime shifts on his conclusions. Thus, more than a century ago, there was considerable insight into non-stationarity in economics data.

By the early 1970s, large econometric models often produced less accurate forecasts than simple time-series models which had been built without any reference to economic theory: see e.g., Phillip Cooper (1972) and Charles Nelson (1972). The specifications of the equations in these large simultaneous models were not very dynamic, and contained few lagged endogenous variables. Working with 
Paul Newbold, Granger and Newbold (1974) observed that all too often, the main criteria for selecting each equation by economic modelers was their goodness-of-fit (measured by the value of $\mathrm{R}^{2}$, the squared coefficient of determination), and the signs and 'significances' of regression estimates. From this starting-point, Granger re-investigated the problem of 'nonsense regressions' (but called 'spurious regressions'). Consider a data generation process (DGP) for two independent non-stationary variables ( $y_{t}$ and $x_{t}$ say), each a random walk of the form:

$$
\left(\begin{array}{c}
y_{t} \\
x_{t}
\end{array}\right)=\left(\begin{array}{c}
y_{t-1} \\
x_{t-1}
\end{array}\right)+\left(\begin{array}{c}
\epsilon_{t} \\
\eta_{t}
\end{array}\right) \text { where }\left(\begin{array}{c}
\epsilon_{t} \\
\eta_{t}
\end{array}\right) \sim \mathbb{I N}_{2}\left[\left(\begin{array}{c}
0 \\
0
\end{array}\right),\left(\begin{array}{cc}
\sigma_{\epsilon}^{2} & 0 \\
0 & \sigma_{\eta}^{2}
\end{array}\right)\right]
$$

where $\mathrm{IN}_{2}[\mathbf{0}, \boldsymbol{\Sigma}]$ denotes a bivariate mean-zero, constant variance $\boldsymbol{\Sigma}$, normally-distributed innovation error. Thus, $y_{t}$ and $x_{t}$ in (1) are independent I(1) variables whose first differences $\Delta y_{t}$ and $\Delta x_{t}$ are $\mathrm{I}(0)$ (in fact, stationary white noise). Regress either variable on the other, as in:

$$
y_{t}=\alpha+\beta x_{t}+u_{t}
$$

Then the regression coefficient $\beta$ usually appears significant, in that the null hypothesis, $\mathrm{H}_{0}: \beta=0$ (i.e., that the coefficient is zero) is rejected about $70 \%$ of the time when a conventionally calculated t-test is applied at $5 \%$ for a sample size of about $T=100$. Thus, the danger of accepting such purely spurious equations as meaningful economic relationships is considerable. Surprisingly, the problem of spurious rejection gets worse as the sample size grows: at $T=1000, \mathrm{H}_{0}: \beta=0$ is incorrectly rejected $90 \%$ of the time in (2) even at a $1 \%$ significance level, despite one's intuition that eventually such unrelated series should 'wander apart' and not appear related.

However, the residuals, $\widehat{u}_{t}$, of an estimated equation like (2) are almost always strongly positively autocorrelated. It has been known since the work of Herman Wold (1952) that the conventionally calculated standard errors of least-squares estimated coefficients could be badly downward biased in such a setting, thereby inflating calculated t-statistics and leading to excess rejection of correct null hypotheses. For regression models with 'strongly exogenous' regressors, an appropriate solution also had a long pedigree, dating back to the famous paper on 'generalised least squares' (GLS) by A.C. Aitken (1935). The standard test at the time in that context was the Durbin-Watson statistic, DW (see James Durbin and Watson, 1950, 1951), which should have a value around 2 under the null of serial independence, and zero for perfect serial correlation. Granger and Newbold (1974) noted that a warning signal for nonsense regressions was $\mathrm{R}^{2}>D W$. Thus, they alerted investigators who had estimated equations with the above properties against interpreting the results as necessarily having substance (there was a large number of equations in extant models with $\mathrm{R}^{2}>D W$ ). They argued that econometricians could not ignore the dynamic properties of the variables they analyzed, especially when the time series were non-stationary. Emphasizing the importance of dynamic properties of economic relationships during a time when econometric models were still essentially static, was a valuable contribution, and their work became widely cited. Granger also underlined the importance of testing the estimated model as good econometric practice, being in this respect ahead of most of his colleagues, and initiating a theme he has pursued ever since (see e.g., Granger and Deutsch, 1992, and Granger, 1999, 2001).

Their results not only confirmed that apparently significant relationships between economic variables may well be spurious if the variables in question are non-stationary, a positive solution was proposed: the problem is usually much less severe - or practically nonexistent - if first differences of variables are used instead of the levels. That is, one postulated instead of (2) the relationship:

$$
\Delta y_{t}=\gamma+\theta \Delta x_{t}+\xi_{t}
$$


Three consequences follow from the formulation in differences in (3). First, if the original variables were $\mathrm{I}(1)$, their differences would be $\mathrm{I}(0)$, so from the perspective of the nonsense regressions problem being due to unit roots in the DGP (1), that difficulty should be removed. Secondly, differencing greatly attenuates large positive residual serial correlation, as was well known since Donald Cochrane and Guy Orcutt—indeed that was the solution Orcutt and Cochrane (1949) had really recommended, not the procedure since associated with their name (see Duo Qin and Gilbert, 2001). Thirdly, and unfortunately, the specification in (3) created a dilemma: while differencing variables was a feasible alternative from a statistical point of view, economic theory was mostly formulated in levels. In particular, defining an economic equilibrium usually required the levels of the variables. Granger and Newbold (1974) suggested that statisticians who worked with differenced data and dynamic models had important lessons to teach economists who used simultaneous-equations models based on the levels of variables for forecasting. Earlier, Frank Fisher (1962) had recommended differencing for short-run analysis.

Granger and Newbold (1977b) followed up this line of argument to propose a time-series approach to econometric model building, which re-iterated their earlier critique of spurious regressions and its solution by differencing. They also showed that residual serial-correlation corrections of the CochraneOrcutt variety did not resolve the nonsense-regressions problem despite being approximations to GLS (but see the comments in the previous paragraph). One may note the 'corroborating' evidence that if economics variables were generated as in (1), then so-called naive forecasting devices like a random walk (often with an intercept, so corresponding to a 'constant change' specification like $\Delta y_{t}=\gamma$ ) would outperform, because they actually represented the DGP. Thus, a consistent story emerged supporting the specification of dynamic relationships in differences, and thereby creating a major problem for economic theories formulated between the levels of the variables.

Terence Gorman, then at LSE and almost Olympian in his knowledge of the literature, had drawn the attention of the School's econometricians to the earlier work by Yule noted above. At the same time, the burgeoning literature on unit roots following from George Box and Jenkins (1970) prompted considerable work at the School on that issue, none of which suggested it was very important if properly handled (see e.g., Hendry and Mizon, 1978). For example, in his discussion of Granger and Newbold (1977b), Hendry (1977) noted that adding the lagged values of the two variables $y_{t}$ and $x_{t}$ essentially resolved the 'spurious regressions' problem. Thus, instead of (2), estimate:

$$
y_{t}=\delta_{0}+\delta_{1} x_{t}+\delta_{2} y_{t-1}+\delta_{3} x_{t-1}+v_{t} .
$$

A Monte Carlo simulation readily demonstrates the efficacy of this solution (using PcNaive from Jurgen Doornik and Hendry, 2001). The rejection frequencies for the null hypotheses that $\mathrm{H}_{0}: \delta_{1}=0$ and $\mathrm{H}_{0}: \delta_{3}=0$ are indeed approximately $\alpha \%$ under the null for a t-test which rejects for the conventional critical value of $c_{\alpha}$. Figure 1 panels (a)-(d) shows the densities of the test statistics for the four coefficients in (4) based on 50000 replications for the DGP in (1) when $c_{\alpha}=2$ (so $\alpha=0.05$ ) for $T=100$. In (a), almost all t-values for $\mathrm{H}_{0}: \delta_{2}=0$ are large and positive, correctly rejecting the null since in fact $\delta_{2}=1$. In (b), the distribution of the test of $\mathrm{H}_{0}: \delta_{0}=0$ shows an odd-looking bimodal distribution, with almost 30\% of the t-values exceeding 2 in absolute value. Such a finding might have rung warning bells had it been analyzed, since there are deep, but at the time unknown, reasons why the procedure in (4) worked, which we will come to later (see e.g., Chris Sims, Stock and Watson, 1990, and Juan Dolado, Jenkinson and Sosvilla-Rivero, 1990). Most importantly, panels (c) and (d) show there is simply no excess rejection of the nulls $\mathrm{H}_{0}: \delta_{1}=0$ and $\mathrm{H}_{0}: \delta_{3}=0$ : i.e., no 'nonsense relations' problem.

Moreover, under the alternative, the procedure also works well. That is, if the process $x_{t}$ is a random 

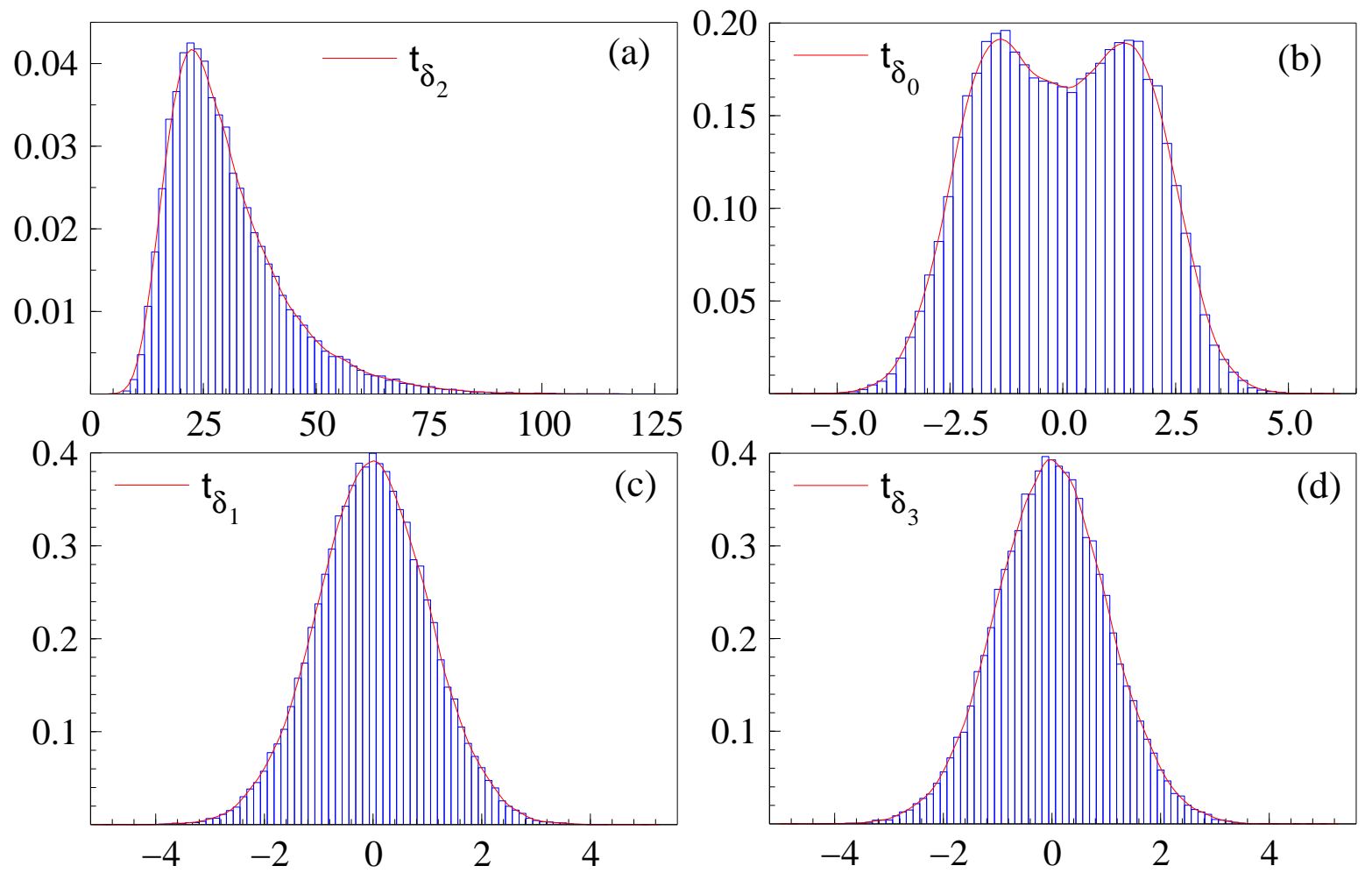

Figure 1 Densities of t-tests under the null of no relation.
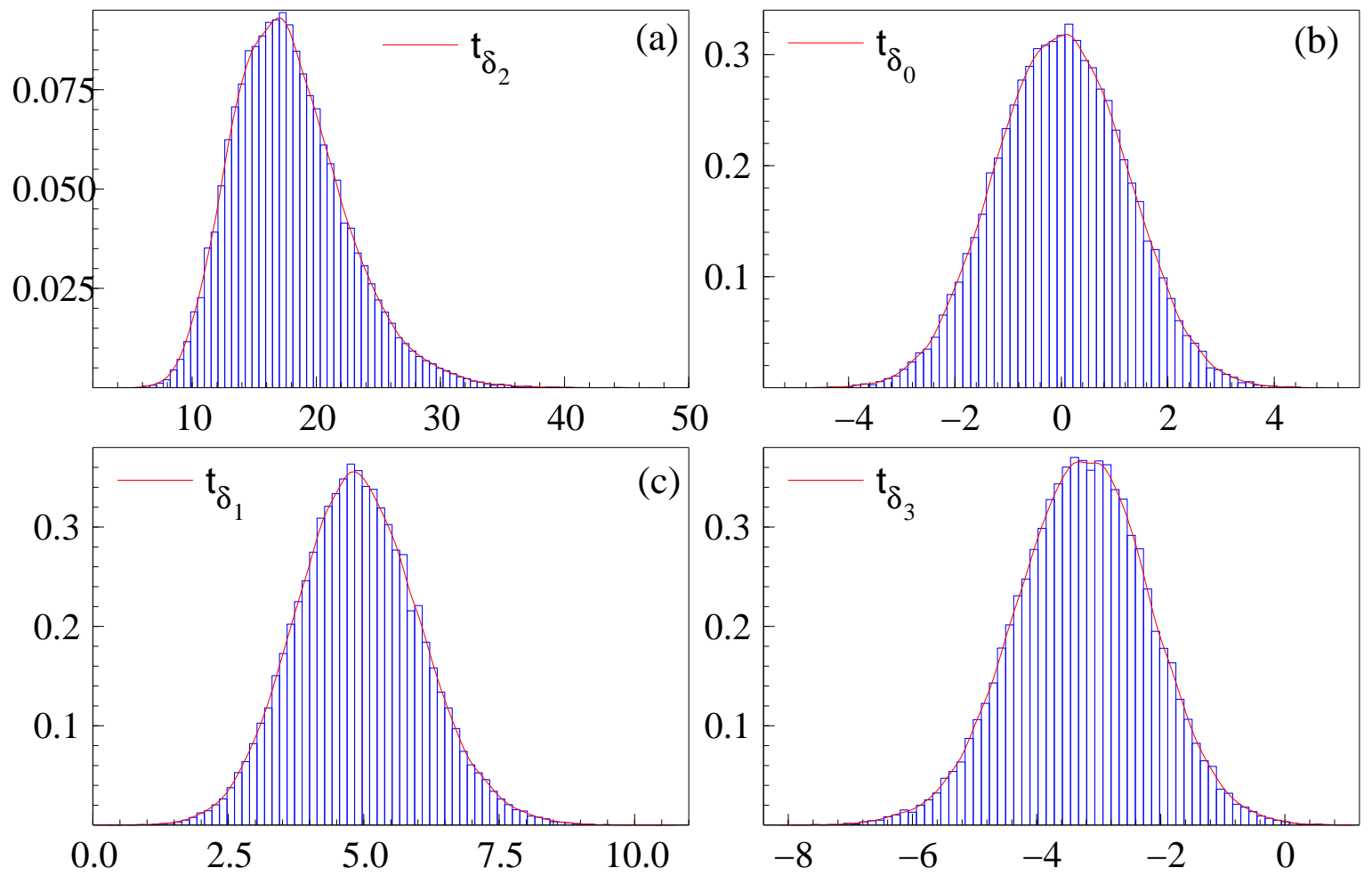

Figure 2 Densities of t-tests under the alternative of a relation.

walk, but instead of (1), $y_{t}$ is generated by:

$$
y_{t}=\delta_{0}+\delta_{1} x_{t}+\delta_{2} y_{t-1}+\delta_{3} x_{t-1}+w_{t}
$$


where $w_{t} \sim \operatorname{IN}\left[0, \sigma_{w}^{2}\right]$ and $\left|\delta_{2}\right|<1$, then the relationship is found with power to correctly reject the null depending on the values of the parameters, but being high at empirically relevant parameter values and reasonable sample sizes. For example, when $\delta_{1}=0.5, \delta_{2}=0.9$ and $\delta_{3}=-0.4$ (as in Davidson, Hendry, Srba and Yeo, 1978, usually known as DHSY), we have the outcomes shown in the four panels of figure 2 for $T=100$. Other than for the constant, which is indeed zero, and is now correctly rejected $5 \%$ of the time, only tiny parts of the other three distributions cross the origin. The formulation in (5) is, in current terminology, a cointegrating relation when $\left|\delta_{2}\right|<1$. In Hendry (1980), the deliberate creation and detection of nonsense regressions establishes the level of understanding of this 'problem'.

Nevertheless, given this background, one might reasonably have concluded that:

(1) there was no case to answer on nonsense regressions;

(2) nonsense regressions merely represented massive dynamic mis-specification which was easily avoided;

(3) unit roots per se were relatively unproblematic;

(4) differencing killed the patient rather than cured the disease for economics;

(5) regression remained an appropriate procedure for I(1) variables in levels.

In comparison, the discrepancies noted above seemed small and likely to be explained in due course...

\section{Equilibrium correction}

Indeed, for the homogeneous (but quite common) special case that $\delta_{1}+\delta_{2}+\delta_{3}=1$, Hendry (1977) noted that (5) could be expressed as:

$$
\Delta y_{t}=\delta_{0}+\delta_{1} \Delta x_{t}+\left(\delta_{2}-1\right)\left(y_{t-1}-x_{t-1}\right)+w_{t} .
$$

Lawrence Klein (1953) already understood this trick in terms of his 'great ratios', where the nonstationarity in the individual series 'cancelled' in their (log) ratio, which was non-trending and well behaved in comparison. In fact, the idea of a long-run relationship in levels in an equation otherwise in first differences like (6) as a specification for agent behaviour dates back to Denis Sargan (1964). The policy analysis literature predated even that, since (6) is also interpretable as having derivative and proportional control mechanisms (corresponding to $\delta_{1}$ and $\left(\delta_{2}-1\right)$ respectively): see, in particular, Bill Phillips (1954, 1957).

At the most elementary level, surely one could first generate $x_{t}$ by (1) and then $y_{t}$ by (6) for appropriate parameter values, finally adding $w_{t} \sim \operatorname{IN}\left[0, \sigma_{w}^{2}\right]$, to ensure that the relation was genuine? However, viable inference procedures must work correctly both under the null hypothesis of no relation, as well as under the alternative. Under the null that $y_{t}$ is just a random walk as in (1), one should find $\delta_{1}=\left(\delta_{2}-1\right)=0$; if the differences of $y_{t}$ and $x_{t}$ were related, but not their levels, then $\delta_{1} \neq 0$ whereas $\left(\delta_{2}-1\right)=0$; and if the levels had a homogeneous long-run as in (6), then $\left(\delta_{2}-1\right) \neq 0$ (where the value of $\delta_{1}$ depends on the short-run response of agents). Given the outcome for (5), the first two claims may seem plausible: but they are incorrect, at least on the basis of conventionally applied critical values. We can easily check them again by Monte Carlo simulation, first considering (1) as the DGP, but fitting (6) as the model.

In the first case of no relation, panel (a) of figure 3 reveals that most values of $\mathrm{R}^{2}$ are quite small, consistent with no relationship: however, any values above 0.075 are in fact significant at the $5 \%$ level on conventional criteria. Next, $\mathrm{H}_{0}: \delta_{1}=0$ is rejected approximately $5 \%$ of the time (panel (c)), so that is fine. Unfortunately, both $\mathrm{H}_{0}: \delta_{0}=0$ and $\mathrm{H}_{0}: \delta_{2}=1$ (shown in panels (b) and (d) respectively) 
are rejected more than $15 \%$ of the time at a nominal significance level of $5 \%$. In the second case, $\mathrm{H}_{0}$ : $\delta_{2}=1$ is rejected $22 \%$ of the time, so the excess rejection gets worse, albeit not a par with that in (2). Nevertheless, under the null, one would falsely think that a relationship existed more than a fifth of the time. That all is well in (5) but not in (6) - despite the transformation to the latter being logically entailed under the null by the former-is symptomatic of the need for careful analysis once data are not stationary. ${ }^{1}$.
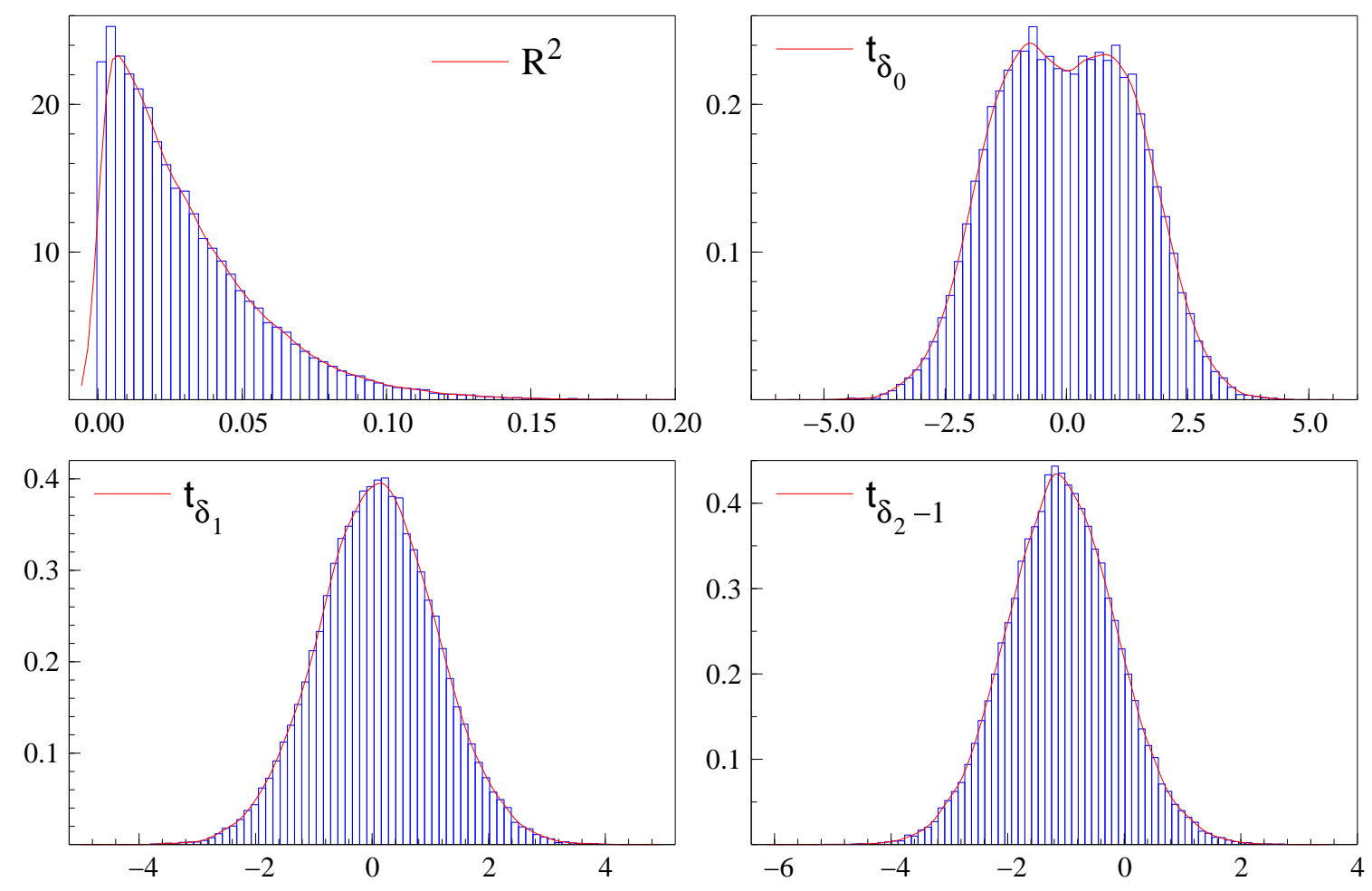

Figure 3 Densities of t-tests for the null of no relation in (6).

Building on much of the literature cited above, Hendry and Anderson (1977) explicitly aimed at integrating 'long-run equilibrium' theory with a short-run control-theoretic model of dynamic disequilibrium adjustment, based on the claim that 'there are ways to achieve stationarity other than blanket differencing'. The solution of their theoretical model of optimizing behaviour by UK Building Societies (mutual mortgage lending institutions similar to Savings and Loans associations) was precisely of the form in (6) for the logs of the variables, so $\left(y_{t-1}-x_{t-1}\right)$ represented a log ratio. This shows up in a re-analysis of the data on mortgage lending $(M)$ and deposits $(D)$ by UK Building Societies, illustrated in figure 4 over the sample 1955(1)-1984(4). ${ }^{2}$

The levels nominal data are highly non-stationary (panel (a)), and indeed explosive: the ratio of the last observation to the first is more than 50-fold. A log transformation merely converts the series to look like linear trends, although it does at least remove the apparent explosive behaviour. Even working in constant price terms does not remove the strong trends, but does reveal that they are not just deterministic

\footnotetext{
${ }^{1}$ These apparently anomalous outcomes were later explained in part by Dickey and Fuller $(1979,1981)$ and Evans and Savin $(1981,1984)$ who demonstrated the need for different critical values when testing null hypotheses involving unit roots. However, they also relate to the deeper story to come

${ }^{2}$ Later conversions of the status of many Building Societies to Banks make a long series problematic.
} 

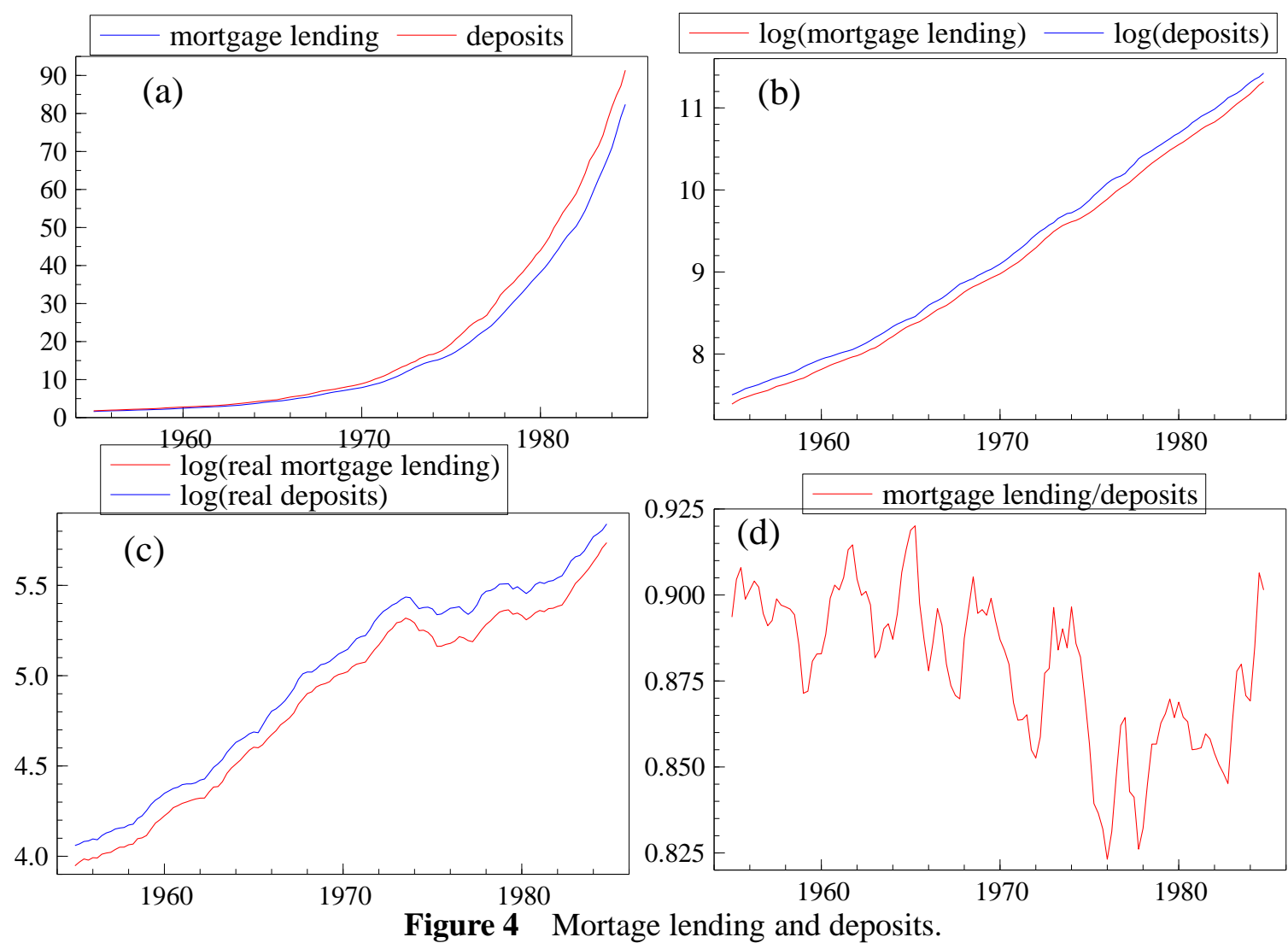

linear effects (panel c). However, the ratio of lending to borrowing $(M / D)$ in panel d does not trend, and lies within the relatively small interval of $0.825-0.925$, a massive reduction from 50 -fold changes. This looks like another 'great ratio', and like many of those, is virtually bound to lie in a small interval, whatever happens to the levels, if Building Societies are to stay solvent. Moreover, such ratios have the same value for real or nominal variables, so will not be affected by any potential non-stationarity of price levels. This simple logic underlies most of the notions of 'great ratios', as well as the claim noted above that stationarity can be achieved by ways other than differencing.

The $\log$ of $M / D$ looks even better behaved as shown in figure 5 (a), and ends the period at virtually the same value as it began. The growth rates of nominal and real values of lending and borrowing are shown in panels (b) and (c) respectively; the latter looks relatively stationary on an ocular test, but the former clearly trends, so cannot be stationary. The scatter plot in panel (d) shown with the projections from the regression line to the points, confirms their close contemporaneous relation.

A simple equilibrium-correction model in the logs of the real values (denoted $m-p$ and $d-p$ ) of the form used by Sargan (1964) works remarkably well, as shown in (7):

$$
\begin{aligned}
\Delta \widehat{(m-p)_{t}} & =-\underset{(0.004)}{0.011}+\underset{(0.050)}{0.26} \Delta(m-p)_{t-1}+\underset{(0.052)}{0.76} \Delta(d-p)_{t}-\underset{(0.032)}{0.082}(m-d)_{t-1} \\
\mathrm{R}^{2} & =0.76 \widehat{\sigma}=0.86 \% \mathrm{~T}=118
\end{aligned}
$$

None of the diagnostic statistics for parameter constancy, normality, residual serial independence, or residual homoscedasticity rejects: with a residual standard deviation of under $1 \%$, the fit closely tracks the changes in real lending. Moreover, DHSY found the same model form accounted for the peculiar behaviour of consumers' expenditure in the UK, which had marked seasonal changes, and where savings 

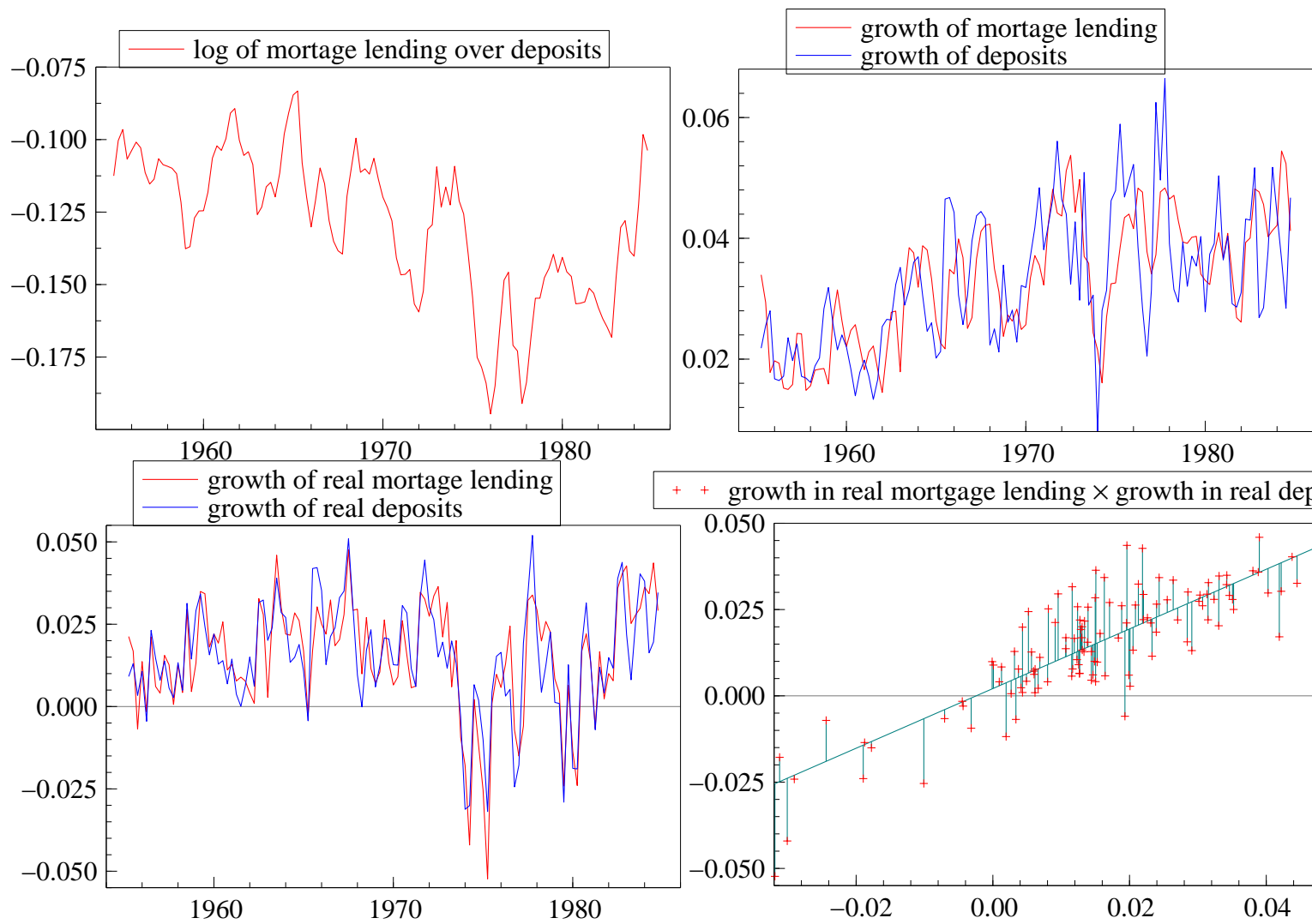

\section{$1960 \quad 1970 \quad 1980$}
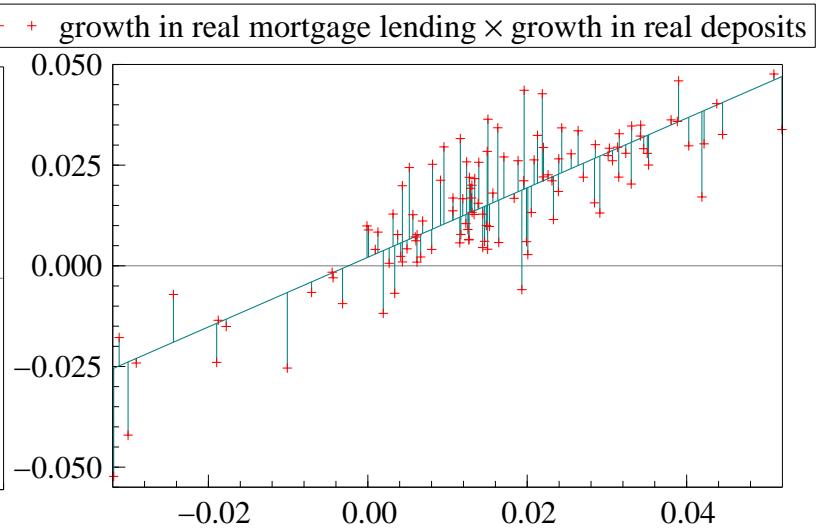

Figure 5 Mortage lending and deposits ratios and growth.

rates rose with increased inflation. Thus, equilibrium-correction models (EqCMs) were well known by the mid-1970s, and were proving a successful class of model for non-stationary data. With a little economics (using logs of real variables), a simple transform (growth rates and the lending-borrowing ratio), the four coefficients of (7) seem to completely tame the 'unruly' behaviour of the levels in figure 4 panel (a). Combined with the results noted at the end of the previous section, it seems reasonable to extend our conclusions to:

6. models with long-run equilibria that avoided any problems were easily formulated; and

7. equilibrium-correction models established a viable econometrics for non-stationary data.

\section{Cointegrated variables}

Fortunately, Clive Granger did not accept these claims, and remained critical of the class of model in (7). First, he emphasized that although ocular econometrics was undoubtedly valuable, beauty lay in the eye of the beholder, not the data (see his discussion of Hendry and Richard, 1983). For example, is the log-ratio in figure 5 (a) really stationary? Secondly, in Sargan's, and most subsequent work before Granger's contribution, the (log) linear combinations of level variables had known coefficients, and the stationarity of that combination was just assumed. Thirdly, such claims were hardly sufficient and crucial hypotheses required formal tests. The simplest test of the claim that (say) $(m-d)$ is not I(1) would be that based on the work of Wayne Fuller (1976), and David Dickey and Fuller (1979, 1981), and applying their approach here (using an appropriate statistic, called the ADF test, with three lagged differences) does not reject the null of a unit root. This casts serious doubt on the equilibrium-correction model in (7).

Fourthly, Granger discovered that all the previous analyses had missed a key point. The I(1) data 
properties in (say) (5) were taken as given 'outside' of the postulated model, rather than entailed by the process itself, as in (1) (say): that is, the model did not imply that the data had to be I(1), and (5) could equally apply to an I(0) data set. If one also postulated an econometric model for $x_{t}$ other than (1) (i.e., $(d-p)_{t}$ in (7)), then two possibilities arose. In the first, $x_{t}$ (or $(d-p)_{t}$ ) had its own separate feedback, dependent on another unmodelled variable, say $z_{t}$ (perhaps real disposable income for deposits). Any non-stationarity in $x_{t}$ then had to be inherited from $z_{t}$, passing the buck on the origins of the unit roots. In the second, however, say the equation for $x_{t}$ took the form in (8):

$$
\Delta x_{t}=\lambda_{0}+\lambda_{1}\left(x_{t-1}-\kappa y_{t-1}\right)+\zeta_{t}
$$

where $\kappa \neq 1$. Then the long-run equilibrium of the bivariate process for $y_{t}$ and $x_{t}$ determined by (6) and (8) was a point, and the process does not have a unit root, contradicting the manifest fact that the data are I(1). The final alternative is that $\kappa=1$, so the same feedback occurs in both models, and now the long-run relation becomes the trajectory $x=y$. In this last case, the data must be $\mathrm{I}(1)$, and that feature is self-generated, not needing a separate postulate. Thus, if there fewer levels feedbacks (i.e., one) than variables (here 2), the process cannot be stationary, and simultaneously, the feedback must eliminate one unit root.

As he records in Phillips (1997), Granger set out to prove that, in general, linear combinations of I(1) variables like $x_{t}-\kappa y_{t}$ would be I(1), so EqCMs were not a viable model class. Thus, combinations like $(m-d)$ in (7) should not lead to rejections on tests for unit roots, as they had to be I(1). In the process of trying to do prove this, he instead established the conditions under which 'co-integration' could occur, whereby some linear combinations were I(0), or more generally, of a lower order of integration than the original variables. The Granger representation theorem is the main result, and the centerpiece of modern econometric analyses of non-stationary processes. In his path-breaking paper, cited more than 250 times, Granger (1981) proposed an elegant solution. Suppose the dependent variable is a first difference like $\Delta y_{t}$ and can be considered stationary. If the right-hand side of an equation contains levels of variables, say first lags of both the dependent and an independent variable $\left(y_{t-1}, x_{t-1}\right)$, then these must be nonstationary, albeit stationary if differenced once. Thus, an equation like (5) can be internally consistent if and only if a linear combination of the two levels variables is $I(0)$ : conversely, if it is $I(0)$, then both sides of the equation are stationary, and the formulation is internally consistent. A stationary linear combination of I(1) variables is a special case, but when it holds, such a pair of level variables is called cointegrated.

The condition that there are fewer levels feedbacks ( $r$ say) than variables $(n)$, which generates both integrated variables and cointegrated combinations, is a reduced-rank requirement on the long-run matrix of the dynamics. If we consider what is often called the 'toy' model of an $n$-dimensional I(1) process, written as:

$$
\Delta \mathbf{y}_{t}=\boldsymbol{\tau}+\boldsymbol{\pi} \mathbf{y}_{t-1}+\boldsymbol{\epsilon}_{t} \text { where } \boldsymbol{\epsilon}_{t} \sim \mathrm{IN}_{n}\left[\mathbf{0}, \boldsymbol{\Omega}_{\epsilon}\right]
$$

then the rank of the $n \times n$ matrix $\pi$ is fundamental. If $\boldsymbol{\pi}$ is of rank $n$, then the process in (9) is stationary; but if $\operatorname{rank}(\boldsymbol{\pi})=r<n$, then $\mathbf{y}_{t}$ is $\mathrm{I}(1)$ and there are $r \mathrm{I}(0)$ linear combinations, say $\boldsymbol{\beta}^{\prime} \mathbf{y}_{t}$, where $\boldsymbol{\beta}$ is $r \times n$ of rank $r$. Then, we can express $\boldsymbol{\pi}=\boldsymbol{\alpha} \boldsymbol{\beta}^{\prime}$ where $\boldsymbol{\alpha}$ is also $r \times n$ of rank $r$ and represents the 'strength' of the feedbacks of the various cointegrating combinations onto each change. This general condition underpins much of the subsequent work: recent surveys are provided by Hendry and Juselius (2000, 2001) and S. (2000) inter alia. This notion also relates back to an earlier literature where reduced rank occurred in the estimation of simultaneous equations (see e.g., Ted Anderson and Rubin, 1949), and in multivariate statistical models (see e.g., Box and Tiao, 1977, and Bewley, Orden, Yang and Fisher, 1994 for a recent analysis). 
This notion opened up a valid way of incorporating economic theory (expressed by relationships in levels of variables) into dynamic econometric equations in first differences. The stationary linear combination in levels may be interpreted as an equilibrium long-run relationship, whereas the shortterm adjustment process towards the equilibrium is characterized by differenced (and lagged) variables. Cointegration is perhaps the most important single innovation in time-series econometrics since the probability foundations by Nobel Laureate Trygve Haavelmo in the 1940s (see Haavelmo, 1944).

Seen against that background, Granger's idea was a major generalization of Sargan's. However, it arose in a different context, because Granger's starting-point was the aim to build consistent econometric equations containing both levels and first differences as variables, rather than ensure homogeneous longrun solutions. While it started a vast and continuously expanding literature, Granger (1981) did not propose statistical tests of whether or not a pair of non-stationary variables is cointegrated. This he did with Andrew Weiss in Granger and Weiss (1983), suggesting a technique based on the same idea as the previous unit-root tests in econometrics, thereby providing a first step in making the idea of cointegration operational. Granger and Weiss also generalized the concept of cointegration to several variables. Finally, they provided the first empirical examples in which a non-cointegration test was applied to pairs and triples of economic time series.

To complete his work, Granger and Rob Engle (with whom he shared the Prize for 2003) proposed a way of estimating equations containing potentially cointegrated relationships. Their two-step estimation technique was presented in Engle and Granger (1987), and while soon overtaken by full maximum likelihood methods (see e.g., Søren Johansen, 1988, 1995), and methods which corrected for biases that would otherwise ensue (see Phillips and Hansen, 1990), was a major milestone, because it opened the gates to a flood of new theory and applications. With feasible estimation methods, cointegration became enormously popular among applied econometricians. The SSCI database shows that Engle and Granger (1987) has been cited about 200 times per year since its appearance. Gradually, large simultaneousequations models have been revised to contain cointegrated linear combinations of level variables and more adequate short-term dynamics in differences, implementing Granger's research program.

We can now return to the example of mortgage lending and deposits. Whether ADF tests or a bivariate analysis based on Johansen (1988) are used, there is no evidence that $(m-d)$ is anything other than I(1): a unit root in that series cannot be rejected, and cointegration between the levels cannot be established at any reasonable significance level. At first sight, that finding might be thought to suggest that the tests have low power to reject the null, and such a possibility cannot be excluded. Prior to establishing the Granger representation theorem, the 'low power' claim was possibly the only escape from such apparent anomalies. But another aspect of the importance of his breakthrough is that the above finding is almost certainly not an anomaly, but an inherent feature of the data: $m$ and $d$ are not $\mathrm{I}(1)$ but $\mathrm{I}(2)$. This implies that their differences are I(1) and the earlier graphs suggest that $\Delta m$ and $\Delta d$ do trend over the sample, so are not stationary. If $(m-d)$ and $\Delta(d-p)$ are I(1), 'multi-cointegration' may be needed to establish I(0) combinations, such as $(m-d)-\rho \Delta(d-p)$, leading to the basic specification being in second differences.

$$
\begin{aligned}
\Delta^{2} \widehat{(m-p)_{t}=} & -\underset{(0.08)}{0.40} \Delta^{2}(m-p)_{t-1}+\underset{(0.06)}{0.72} \Delta^{2}(d-p)_{t}+\underset{(0.07)}{0.36} \Delta^{2}(d-p)_{t-1} \\
& -\underset{\substack{(0.03) \\
0.14}}{0}(m-d-1.2 \Delta(d-p)-0.147)_{t-1}+\text { seasonals } \\
\mathrm{R}^{2}= & 0.78 \widehat{\sigma}=0.78 \% \mathrm{~T}=117
\end{aligned}
$$

The feedback term is significant and is now judged I(0) on ADF tests (so a unit root can be rejected), and 
none of the residual diagnostic tests is significant (although there is slight evidence of heteroscedasticity). Generally, almost $80 \%$ of the acceleration in real mortgage lending is accounted for by the model, with a residual standard deviation of under $0.8 \%$. In a static equilibrium (i.e., zero growth), (10) implies that $m=d-0.147$ so about $85 \%$ of deposits are relent on mortgages; whereas if real deposits are growing rapidly (say $4 \%$ ), then only $80 \%$ is lent, rising to $90 \%$ if real deposits fall at $4 \%$. Figure 6 records the scatter plot of $(m-d)$ against $\Delta(d-p)$ in panel (a), showing their strong negative correlation; panel (b) shows both second-differenced time series $\Delta^{2}(m-p)_{t}$ and $\Delta^{2}(d-p)_{t}$; panel (c) reports the corrected feedback term $(m-d-1.2 \Delta(d-p)-0.147)$; and panel (d) the fitted and actual values from (10).

Hindsight analysis of the economics of Building Society behaviour suggests just such a cointegration vector. As Building Societies are legally required to maintain a minimum ratio $\phi$ of reserves $(R)$ to assets (primarily deposits $D$ ) so that $R_{t}=\phi D_{t}$ then:

$$
\Delta(r-p)_{t}=\Delta(d-p)_{t}
$$

Thus, a rise in real deposit inflows requires a matching rise in real reserves, which either requires raising the interest rate charged on mortgages relative to that paid on deposits (so lowering the lending ratio by a price effect), or lowering mortgage lending in order to invest in outside assets if their yields are higher than the interest rate charged on mortgages, again lowering the lending ratio (by a quantity effect). In both cases, a negative impact of $\Delta(d-p)$ on $m-d$ is expected, consistent with the I(2) to I(0) transformation in (10). Reconsidering figure 4 over the sub-sample to 1975:4, a strong downward trend in the lending ratio is apparent during the period of rapid real deposit growth, and so its mean was not constant over that period.

Let us review the various tentative conclusions that had apparently been legitimately drawn above.

1. There was a case to answer on nonsense regressions despite earlier analyses and our ability to create and detect them: a full analysis was only provided by Peter Phillips (1986).

2. Unit roots per se are problematic, and need separate critical values, dependent on the dynamics, the presence of deterministic terms, and how they are modeled: the accuracy of critical values in finite samples also depends on the 'closeness' of the process to I(2).

3. Nonsense regressions did suffer from dynamic mis-specification, but a proper analysis of relationships between integrated variables was not so easily developed (see James Stock, 1987).

4. Investigating only differenced data series was not a viable route for economics where equilibrium theories abounded, but those theories still need revamped for an integrated world.

5. Regression does remain an appropriate procedure for many aspects of I(1) variables in levels, but only if hypotheses involving unit roots are never tested. This explains the odd switch in rejection frequencies between (5) and (6): $\mathrm{H}_{0}: \delta_{2}=1$ corresponds to such a test, so conventional critical values are incorrect, whereas in the tests on (5), another untested variable 'absorbed' the non-stationarity (see Sims et al., 1990).

6. Models with equilibria that avoided the problem were not so easily formulated: without a generic concept of cointegration applicable to higher degrees of integration, many problems would have remained mysterious. For example, Granger's critique of the money-demand 'error-correction' term noted above transpired to be well founded, as it was still I(1), having cointegrated from I(2) to I(1) as with mortgages and deposits, but still needing additional differences to become I(0) (see e.g., Harbo, Johansen, Nielsen and Rahbek, 1998). Thus, testing for cointegration is essential, and can clarify theory models. 

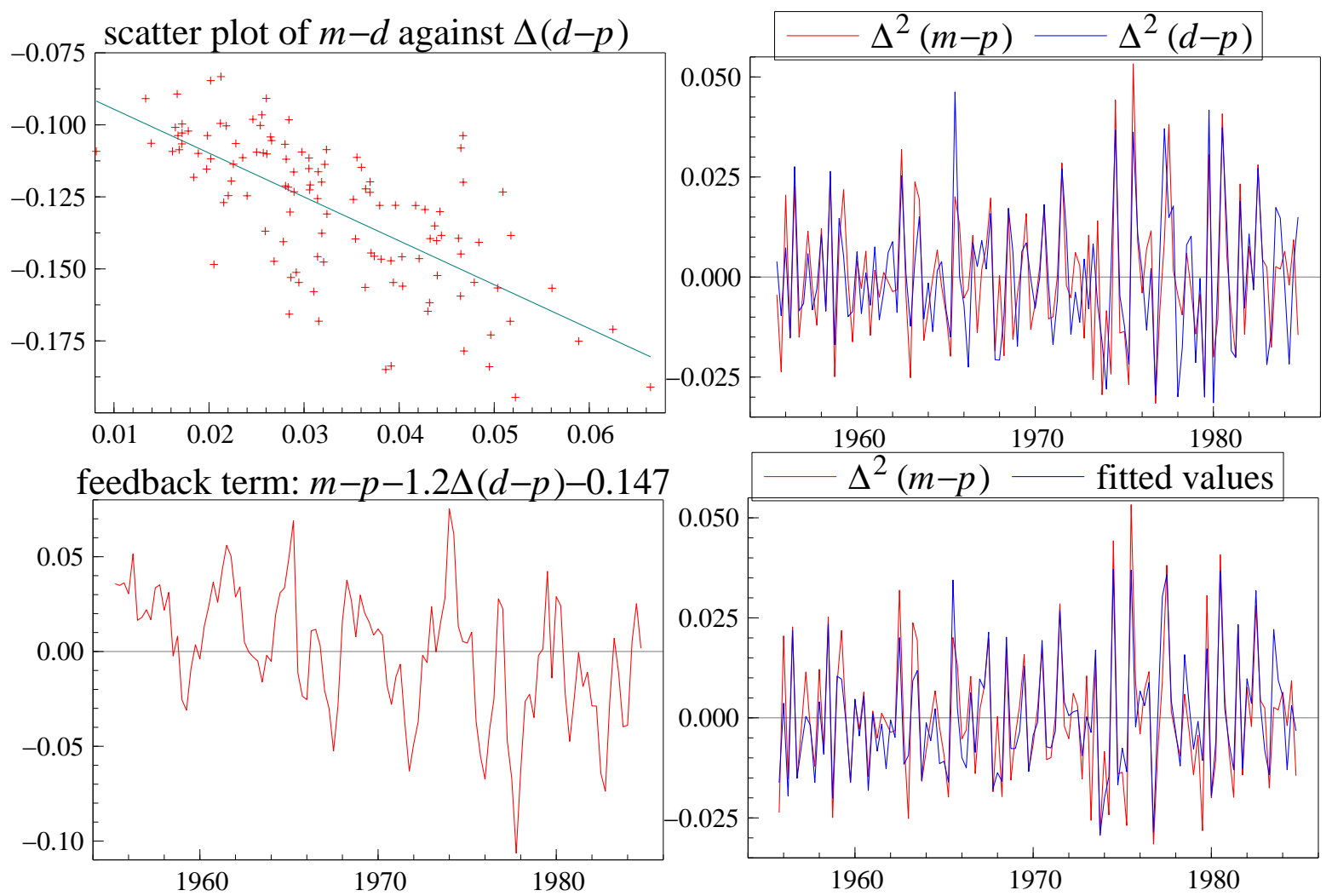

Figure 6 Mortage lending to deposits ratios, acceleration, and fit.

The apparently small discrepancies were indeed handled in due course...by a revolution in our understanding: much had remained, and by his persistence, Granger threw immense light on the entire problem of cointegration and equilibrium correction.

Cointegration is basically a linear concept, and the classical assumption in empirical work has been that drift towards the equilibrium, postulated by models with cointegrated variables, is symmetric: the strength of attraction is a linear function of the distance of the system from the equilibrium. Granger has also investigated non-linear cointegration, loosening the symmetry assumption. This is sometimes necessary in macroeconomics: planned inventories and orders, for example, help to smooth production, so have asymmetric effects - see Granger and Lee (1991), Granger and Swanson (1995), and Granger (1996).

An alternative interpretation of why two series are cointegrated is that there exists a 'common permanent component' that drives both series in the long-run. Gonzalo and Granger (1995) argue that such a common component can be written as a linear combination of the original series, for which one observable counterpart is the linear combination formed by the vector orthogonal to the adjustment vector (i.e., $\boldsymbol{\alpha}$ in the $\mathrm{EqCM}(9)$ above): also see S. (1995).

We now turn to briefly consider some of the many other contributions Granger has made to theoretical and empirical econometrics.

\section{Granger causality}

The first important line of research that Granger undertook is concerned with causal relationships between economic variables. In Granger (1969), in a highly influential paper, Granger pointed out that previous definitions of causality in econometrics had to do with the causal interpretation of simultaneous 
equations systems, usually 'instantaneous' causality. The notion of stochastic variables played a minor role. Granger did not consider this satisfactory, and gave stochastic variables and the 'arrow of time' a central role in the definition (excluding purely deterministic processes from his discussion of causality).

Granger's definition of causality was based on the concept of the prediction variance of a stationary series. Formally, if the joint distribution of a subset of the observable variables is altered by eliminating the history of other variables, then that second group causes the first. Loosely speaking, the first group of economic variables can be predicted more accurately with the second variables than without them. Using that as the basis for an operational approach, Granger proposed testing whether a second group of variables caused other variables by checking if their addition improved predictability. What makes this definition attractive is that it is operational: it is possible to test the hypothesis of non-causality between economic variables by statistical methods. An example of such a test is in Sims (1972).

Its easy implementation made the definition popular, and it has stimulated a remarkable amount of empirical research over the years. It also created controversy as to whether it was a general definition of causality: for a recent analysis, see Hoover (2001). Granger's definition is nowadays commonly referred to as 'Granger causality'. Granger causality is not only an important concept in empirical economic research and policy analysis, it also forms a part of the definition of strong exogeneity (see Engle, Hendry and Richard, 1983); different forms of exogeneity in turn have important forecasting and policy implications in econometric models. Furthermore, if a pair of variables are cointegrated then one of them must Granger-cause the other. One can say that Granger-causality is one of the crucially important concepts of modern econometric theory and model building.

As with many fundamental break-throughs, the importance of 'Granger causality' does not depend purely on whether or not it correctly represents 'genuine causes'. For example, Hendry and Mizon (1999) show that 'Granger-causality' plays a pervasive role in econometrics, and illustrate their claim for ten key areas of econometric modeling, namely marginalizing; conditioning; distributions of estimators and tests; inference via simulation; cointegration; encompassing; forecasting; policy analysis; dynamic simulation; and impulse-response analysis. If Granger had not formulated the notion, the unity of all these disparate topics would not be transparent, although the issues would have remained.

\section{Long-memory models}

At the end of the 1970s, Granger began investigating processes with long memory. These processes have the property that their autocorrelation function decays at a much slower rate than that of a linear autoregressive-moving average (ARMA) process. In work with Roselyn Granger and Joyeux (1980), he defined a new concept, called fractional differencing, and showed how fractionally differenced variables could have the long-memory property. Granger (1980) showed that aggregating autoregressive processes gives rise to fractionally integrated processes. With the increased availability of long financial time series, the importance of long-memory models in econometrics has grown, and been applied to modelling conditional variances - which manifest considerable persistence - consistent with long memory in volatility.

Granger recently demonstrated empirically that on decomposing a high-frequency return time series (such as a stock return, or the return on an exchange rate) into the product of its sign and the absolute value, only the latter process has long-memory: its autocorrelation function decays extremely slowly, whereas the sign is nearly unpredictable - see Granger and Ding (1995), Granger and Sin (2000), and Tina Rydberg and Shephard (2003). The absolute value process also exhibits other interesting features which are seen in many series across markets and countries. This research has started yet another new 
fertile field. For example, the forecastability of the absolute-value series may be investigated, which is interesting from the point of view of forecasting financial risk. Granger's results in this area have also stimulated further research into models for long-memory processes.

\section{Non-linear models}

Granger was again one of the first econometricians to become seriously interested in non-linear timeseries models: see Granger and Andersen (1993) on bi-linear models. That work soon became a standard reference, and has been influential in econometrics via the analysis of non-linear models in empirical macroeconomics. Indeed, it was an important stimulus to his close colleague, Engle, leading to the creation of the model of autoregressive conditional heteroscedasticity (ARCH) for which Engle shared the prize. When Granger and Lee (1989) generalized cointegration to multi-cointegration, they also defined a form of non-linear cointegration, extended by Granger and Swanson (1997) using stochastic unit roots. Empirical work such as Granger's on non-linearities has alerted economists to the fact that some important relationships are non-linear - with implications for economic theory - and conversely, that it is not always necessary to linearize theoretical relationships where non-linear models are anticipated. Granger and Teräsvirta (1993) provide a magisterial overview.

Although most of Granger's work on non-linearities has concentrated on the modeling of conditional first moments, he has also contributed to the literature on conditional variances. He has investigated flexible parameterizations for modeling the conditional variance in situations where GARCH models have proved inadequate, including the power ARCH model in Ding, Granger and Engle (1993) (also see Ding and Granger, 1996).

\section{Economic forecasting}

The class of ARCH and GARCH models is often applied to predicting volatility in stock markets. Since predicting stock market prices has become an important area in applied finance, one must highlight yet another Granger 'first'. In 1970, he published a book with Oscar Morgenstern on econometric aspects of forecasting stock market prices: see Granger and Morgenstern (1970). Economic forecasting per se, and its role in evaluating econometric models, has been one of the recurring themes in Granger's research, and his influence in this field has again been huge. His early work was again joint with Newbold: see Granger and Newbold $(1973,1975,1977$ a) the last of which is one of the classic textbooks in the area. In joint work with Walter Labys and Granger (1970), he investigated commodity price determination.

Another influential observation that Granger made (in Bates and Granger, 1969) is that a combination of forecasts of an economic variable often turns out to be more accurate than the individual predictions which are combined together. At first sight, such an idea seems counter intuitive: one might expect the pooled value to dominate the worst, but not beat the best simply because it includes poor forecasts with some weight. Nevertheless, the latter often occurs, as attested by a large literature on forecasting competitions: for the latest empirical findings, see Makridakis and Hibon (2000) for general time series, and Stock and Watson (1999) for macroeconomic series. Granger's intuition that differential biases would cancel on pooling has been vindicated. This work prompted him to propose various weighting systems for combining forecasts, and again initiated a whole literature, which is still growing, on how to combine economic forecasts.

To judge any economic forecasts - combined or otherwise-one has to know how to evaluate them. Granger $(1999,2001)$ investigated different cost functions and their impacts on econometric modeling, 
including parameter estimation and model evaluation. This extension is an important development beyond mechanistic evaluation, and brings economic analysis into the judgement of costs and benefits of forecast errors. Related work in Granger and Pesaran (2000a, 2000b) and Granger (2001) continues this development.

\section{Conclusion}

His key publications have combined to implement Granger's long-term research agenda of improving the quality of econometric model building by a better match with the empirical evidence. It can be argued that this is one of the more successful research programmes in the history of econometrics, and will be lasting contribution to our discipline.

\section{References}

Aitken, A. C. (1935). On least square and linear combination of observations. Proceedings of the Royal Society of Edinburgh, 55, 42-48.

Anderson, T. W., and Rubin, H. (1949). Estimation of the parameters of a single equation in a complete system of stochastic equations. Annals of Mathematical Statistics, 20, 46-63.

Bates, J. M., and Granger, C. W. J. (1969). The combination of forecasts. Operations Research Quarterly, 20, 451-468. Reprinted in T.C. Mills (ed.), Economic Forecasting. Edward Elgar, 1999.

Bewley, R., Orden, D., Yang, M., and Fisher, L. A. (1994). Comparison of box-tiao and johansen canonical estimators of cointegrating vectors in vec(1) models.. Journal of Econometrics, 64, $3-27$.

Box, G. E. P., and Jenkins, G. M. (1970). Time Series Analysis, Forecasting and Control. San Francisco: Holden-Day.

Box, G. P. E., and Tiao, G. C. (1977). A canonical analysis of multiple time series. Biometrika, 64, $355-365$.

Cooper, J. P. (1972). The predictive performance of quarterly econometric models of the United States. In Hickman, B. G. (ed.), Econometric Models of Cyclical Behaviour, No. 36 in National Bureau of Economic Research Studies in Income and Wealth, pp. 813-947. New York: Columbia University Press.

Davidson, J. E. H., Hendry, D. F., Srba, F., and Yeo, J. S. (1978). Econometric modelling of the aggregate time-series relationship between consumers' expenditure and income in the United Kingdom. Economic Journal, 88, 661-692. Reprinted in Hendry, D. F., Econometrics: Alchemy or Science? Oxford: Blackwell Publishers, 1993, and Oxford University Press, 2000.

Dickey, D. A., and Fuller, W. A. (1979). Distribution of the estimators for autoregressive time series with a unit root. Journal of the American Statistical Association, 74, 427-431.

Dickey, D. A., and Fuller, W. A. (1981). Likelihood ratio statistics for autoregressive time series with a unit root. Econometrica, 49, 1057-1072.

Ding, Z., and Granger, C. W. J. (1996). Modeling volatility persistence of speculative returns: A new approach. Journal of Econometrics, 73, 185-215.

Ding, Z., Granger, C. W. J., and Engle, R. F. (1993). A long memory property of stock market returns and a new model. Journal of Empirical Finance, 1, 83-106. 
Dolado, J. J., Jenkinson, T., and Sosvilla-Rivero, S. (1990). Cointegration and unit roots. Journal of Economic Surveys, 4, 249-273.

Doornik, J. A., and Hendry, D. F. (2001). Interactive Monte Carlo Experimentation in Econometrics using PcNaive. London: Timberlake Consultants Press.

Durbin, J., and Watson, G. S. (1950). Testing for serial correlation in least squares regression I. Biometrika, 37, 409-428.

Durbin, J., and Watson, G. S. (1951). Testing for serial correlation in least squares regression II. Biometrika, 38, 159-178.

Engle, R. F., and Granger, C. W. J. (1987). Cointegration and error correction: Representation, estimation and testing. Econometrica, 55, 251-276.

Engle, R. F., Hendry, D. F., and Richard, J.-F. (1983). Exogeneity. Econometrica, 51, 277-304. Reprinted in Hendry, D. F., Econometrics: Alchemy or Science? Oxford: Blackwell Publishers, 1993, and Oxford University Press, 2000; and in Ericsson, N. R. and Irons, J. S. (eds.) Testing Exogeneity, Oxford: Oxford University Press, 1994.

Engle, R. F., and White, H. (eds.)(1999). Cointegration, Causality and Forecasting. Oxford: Oxford University Press.

Evans, G. B. A., and Savin, N. E. (1981). Testing for unit roots: 1. Econometrica, 49, 753-779.

Evans, G. B. A., and Savin, N. E. (1984). Testing for unit roots: 2. Econometrica, 52, 1241-1269.

Fisher, F. M. (1962). A Priori Information and Time Series Analysis. Amsterdam: North-Holland Publishing Company.

Fuller, W. A. (1976). Introduction to Statistical Time Series. New York: John Wiley \& Sons.

Ghysels, E., Swanson, N. R., and Watson, M. W. (eds.)(2001). Essays in Econometrics. Collected Papers of Clive W.J. Granger 2 Volumes. Cambridge: Cambridge University Press.

Gonzalo, J., and Granger, C. W. J. (1995). Estimation of common long memory components in cointegrated systems. Journal of Business and Economic Statistics, 13, 27-35.

Granger, C. W. J. (1969). Investigating causal relations by econometric models and cross-spectral methods. Econometrica, 37, 424-438.

Granger, C. W. J. (1980). Long memory relationships and the aggregation of dynamic models. JE, 14, $227-238$.

Granger, C. W. J. (1981). Some properties of time series data and their use in econometric model specification. Journal of Econometrics, 16, 121-130.

Granger, C. W. J. (1996). Introducing nonlinearity into cointegration. Revista de Econometria, 16, $25-36$.

Granger, C. W. J. (1999). Empirical Modeling in Economics: Specification and Evaluation. Cambridge: Cambridge University Press.

Granger, C. W. J. (2001). Evaluation of forecasts. In Hendry, D. F., and Ericsson, N. R. (eds.), Understanding Economic Forecasts, pp. 93-103. Cambridge, Mass.: MIT Press.

Granger, C. W. J., and Andersen, A. (1993). Introduction to Bilinear Time Series Models. Göttingen: Vandenhoeck \& Ruprecht.

Granger, C. W. J., and Deutsch, M. (1992). Comments on the evaluation of policy models. Journal of Policy Modeling, 14, 497-516.

Granger, C. W. J., and Ding, Z. (1995). Some properties of absolute returns: An alternative measure of 
risk. Annales d'Économie et de Statistique, 40, 67-91.

Granger, C. W. J., and Joyeux, R. (1980). An introduction to long memory time series models and fractional differencing. Journal of Time Series Analysis, 1, 15-30.

Granger, C. W. J., and Lee, T.-H. (1989). Investigation of production, sales and inventory relationships using multicointegration and non-symmetric error correction models. Journal of Applied Econometrics, 4, 145-159.

Granger, C. W. J., and Lee, T.-H. (1991). Multicointegration. In Engle, R. F., and Granger, C. W. J. (eds.), Long-Run Economic Relationships, pp. 179-190. Oxford: Oxford University Press.

Granger, C. W. J., and Morgenstern, O. (1970). Predictability of Stock Market Prices. Lexington, Massachusetts: D. C. Heath and Company.

Granger, C. W. J., and Newbold, P. (1973). Some comments on the evaluation of economic forecasts. Applied Economics, 5, 35-47. Reprinted in T.C. Mills (ed.), Economic Forecasting. Edward Elgar, 1999.

Granger, C. W. J., and Newbold, P. (1974). Spurious regressions in econometrics. Journal of Econometrics, 2, 111-120.

Granger, C. W. J., and Newbold, P. (1975). Economic forecasting: The atheist's viewpoint. In Renton, G. A. (ed.), Modelling the Economy. London: Heinemann Educational Books.

Granger, C. W. J., and Newbold, P. (1977a). Forecasting Economic Time Series. New York: Academic Press.

Granger, C. W. J., and Newbold, P. (1977b). The time series approach to econometric model building. in Sims (1977), pp. 7-21.

Granger, C. W. J., and Pesaran, M. H. (2000a). A decision-theoretic approach to forecast evaluation. In Chon, W. S., Li, W. K., and Tong, H. (eds.), Statistics and Finance: An Interface, pp. 261-278. London: Imperial College Press.

Granger, C. W. J., and Pesaran, M. H. (2000b). Economic and statistical measures of forecasting accuracy. Journal of Forecasting, 19, 537-560.

Granger, C. W. J., and Sin, C.-Y. (2000). Modelling the absolute returns of different stock indices: Exploring the forecastability of an alternative measure of risk. Journal of Forecasting, 19, 277298.

Granger, C. W. J., and Swanson, N. R. (1995). Further developments in the study of cointegrated variables. Oxford Bulletin of Economics and Statistics, 58, 537-553.

Granger, C. W. J., and Swanson, N. R. (1997). An introduction to stochastic unit-root processes. Journal of Econometrics, 80, 35-62.

Granger, C. W. J., and Teräsvirta, T. (1993). Modelling Nonlinear Economic Relationships. Oxford: Oxford University Press.

Granger, C. W. J., and Weiss, A. A. (1983). Time series analysis of error-correction models. In Karlin, S., Amemiya, T., and Goodman, L. A. (eds.), Studies in Econometrics, Time Series, and Multivariate Statistics, pp. 255-278. New York: Academic Press.

Haavelmo, T. (1944). The probability approach in econometrics. Econometrica, 12, 1-118. Supplement.

Harbo, I., Johansen, S., Nielsen, B., and Rahbek, A. (1998). Asymptotic inference on cointegrating rank in partial systems. Journal of Business and Economic Statistics, 16, 388-399.

Hendry, D. F. (1977). On the time series approach to econometric model building. in Sims (1977), pp. 
183-202. Reprinted in Hendry, D. F., Econometrics: Alchemy or Science? Oxford: Blackwell Publishers, 1993, and Oxford University Press, 2000.

Hendry, D. F. (1980). Econometrics: Alchemy or science?. Economica, 47, 387-406. Reprinted in Hendry, D. F., Econometrics: Alchemy or Science? Oxford: Blackwell Publishers, 1993, and Oxford University Press, 2000.

Hendry, D. F., and Anderson, G. J. (1977). Testing dynamic specification in small simultaneous systems: An application to a model of building society behaviour in the United Kingdom. In Intriligator, M. D. (ed.), Frontiers in Quantitative Economics, Vol. 3, pp. 361-383. Amsterdam: North Holland Publishing Company. Reprinted in Hendry, D. F., Econometrics: Alchemy or Science? Oxford: Blackwell Publishers, 1993, and Oxford University Press, 2000.

Hendry, D. F., and Juselius, K. (2000). Explaining cointegration analysis: Part I. Energy Journal, 21, $1-42$.

Hendry, D. F., and Juselius, K. (2001). Explaining cointegration analysis: Part II. Energy Journal, 22, $75-120$.

Hendry, D. F., and Mizon, G. E. (1978). Serial correlation as a convenient simplification, not a nuisance: A comment on a study of the demand for money by the Bank of England. Economic Journal, 88, 549-563. Reprinted in Hendry, D. F., Econometrics: Alchemy or Science? Oxford: Blackwell Publishers, 1993, and Oxford University Press, 2000.

Hendry, D. F., and Mizon, G. E. (1999). The pervasiveness of Granger causality in econometrics. in Engle, and White (1999).

Hendry, D. F., and Morgan, M. S. (1995). The Foundations of Econometric Analysis. Cambridge: Cambridge University Press.

Hendry, D. F., and Richard, J.-F. (1983). The econometric analysis of economic time series (with discussion). International Statistical Review, 51, 111-163. Reprinted in Hendry, D. F., Econometrics: Alchemy or Science? Oxford: Blackwell Publishers, 1993, and Oxford University Press, 2000.

Hooker, R. H. (1901). Correlation of the marriage rate with trade. Journal of the Royal Statistical Society, 64, 485-492. Reprinted in Hendry, D. F. and Morgan, M. S. (1995), The Foundations of Econometric Analysis. Cambridge: Cambridge University Press.

Hoover, K. D. (2001). Causality in Macroeconomics. Cambridge: Cambridge University Press.

Johansen, S. (1988). Statistical analysis of cointegration vectors. Journal of Economic Dynamics and Control, 12, 231-254. Reprinted in R.F. Engle and C.W.J. Granger (eds), Long-Run Economic Relationships, Oxford: Oxford University Press, 1991, 131-52.

Johansen, S. (1995). Likelihood-based Inference in Cointegrated Vector Autoregressive Models. Oxford: Oxford University Press.

Keynes, J. M. (1940). Comment. Economic Journal, 50, 154-156. Reprinted in Hendry, D. F. and Morgan, M. S. (1995), The Foundations of Econometric Analysis. Cambridge: Cambridge University Press.

Klein, L. R. (1953). A Textbook of Econometrics. Evanston, Ill.: Row, Peterson and Company.

Labys, W. C., and Granger, C. W. J. (1970). Speculation, Hedging and Forecasts of Commodity Prices. London: Heath, and Co.

Makridakis, S., and Hibon, M. (2000). The M3-competition: Results, conclusions and implications. International Journal of Forecasting, 16, 451-476.

Nelson, C. R. (1972). The prediction performance of the FRB-MIT-PENN model of the US economy. 
American Economic Review, 62, 902-917. Reprinted in T.C. Mills (ed.), Economic Forecasting. Edward Elgar, 1999.

Orcutt, G. H., and Cochrane, D. (1949). A sampling study of the merits of autoregressive and reduced form transformations in regression analysis. Journal of the American Statistical Association, 44, $356-372$.

Phillips, A. W. H. (1954). Stabilization policy in a closed economy. Economic Journal, 64, 290-333. Reprinted in Leeson, R. (ed.) A. W. H. Phillips: Collected Works in Contemporary Perspective, Cambridge: Cambridge University Press, 2000.

Phillips, A. W. H. (1957). Stabilization policy and the time form of lagged response. Economic Journal, 67, 265-277. Reprinted in Leeson, R. (ed.) A. W. H. Phillips: Collected Works in Contemporary Perspective, Cambridge: Cambridge University Press, 2000.

Phillips, P. C. B. (1986). Understanding spurious regressions in econometrics. Journal of Econometrics, 33, 311-340.

Phillips, P. C. B. (1997). The ET interview: Professor Clive Granger. Econometric Theory, 13, 253-303.

Phillips, P. C. B., and Hansen, B. E. (1990). Statistical inference in instrumental variable regression with I(1) processes. Review of Economic Studies, 57, 99-125.

Qin, D., and Gilbert, C. L. (2001). The error term in the history of time sries econometrics. Econometric Theory, 17, 424-450.

Rydberg, T. H., and Shephard, N. (2003). Dynamics of trade-by-trade price movements: Decomposition and models. Journal of Financial Econometrics, 1, 2-25.

S., J. (1995). The role of ancillarity in inference for nonstationary variables. Economic Journal, 105, 302-320.

S., J. (2000). Modelling of cointegration in the vector autoregressive model. Economic Modelling, 17, $359-373$.

Sargan, J. D. (1964). Wages and prices in the United Kingdom: A study in econometric methodology (with discussion). In Hart, P. E., Mills, G., and Whitaker, J. K. (eds.), Econometric Analysis for National Economic Planning, Vol. 16 of Colston Papers, pp. 25-63. London: Butterworth Co. Reprinted as pp. 275-314 in Hendry D. F. and Wallis K. F. (eds.) (1984). Econometrics and Quantitative Economics. Oxford: Basil Blackwell, and as pp. 124-169 in Sargan J. D. (1988), Contributions to Econometrics, Vol. 1, Cambridge: Cambridge University Press.

Sims, C. A. (1972). Money, income and causality. American Economic Review, 62, 540-552.

Sims, C. A. (ed.)(1977). New Methods in Business Cycle Research. Minneapolis: Federal Reserve Bank of Minneapolis.

Sims, C. A., Stock, J. H., and Watson, M. W. (1990). Inference in linear time series models with some unit roots. Econometrica, 58, 113-144.

Stock, J. H. (1987). Asymptotic properties of least squares estimators of cointegrating vectors. Econometrica, 55, 1035-1056.

Stock, J. H., and Watson, M. W. (1999). A comparison of linear and nonlinear models for forecasting macroeconomic time series. in Engle, and White (1999), pp. 1-44.

Tinbergen, J. (1940). Statistical Testing of Business-Cycle Theories. Vol. I: A Method and its Application to Investment Activity. Geneva: League of Nations. Reprinted in part in Hendry, D. F. and Morgan, M. S. (1995), The Foundations of Econometric Analysis. Cambridge: Cambridge University Press. 
Wold, H. O. A. (1952). Demand Analysis: A Study in Econometrics,. Stockholm: Almqvist and Wicksell. Yule, G. U. (1897). On the theory of correlation. Journal of the Royal Statistical Society, 60, 812-838.

Yule, G. U. (1926). Why do we sometimes get nonsense-correlations between time-series? A study in sampling and the nature of time series (with discussion). Journal of the Royal Statistical Society, 89, 1-64. Reprinted in Hendry, D. F. and Morgan, M. S. (1995), The Foundations of Econometric Analysis. Cambridge: Cambridge University Press. 